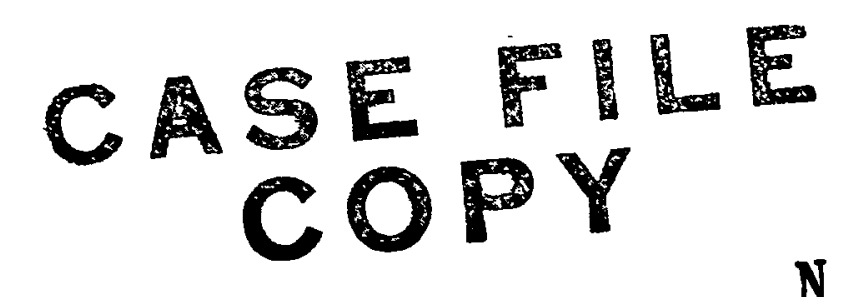

N $73 \quad 32619$

NASA TECHNICAL

MEMORANDUM
NASA TM X-71436

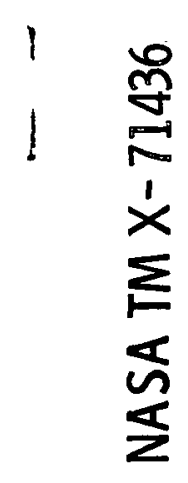

CENTAUR D-IT PROPULSION AND PROPELLANT SYSTEMS

by William E, Goette

Lewis Research Center

Cleveland, Ohio

TECHNICAL PAPER proposed for presentation at

Propulsion Joint Specialist Conference cosponsored by the American Institute of Aeronautics and Astronautics and the Society of Automotive Engineers

Las Vegas, Nevada, November 5 - 7, 1973 


\title{
CENTAUR D-1T PROPULSION AND PROPELLANT SYSTEMS
}

\author{
William E. Goette \\ Head, Propulsion and Propellant Systems Section \\ National Aeronautics and Space Administration \\ Lewis Research Center \\ Cleveland, Ohio
}

\section{Abstract}

The Centaur D-1T is the improved version of the Centaur high energy upper stage which is being integrated with the Titan III booster. Modifications have been made to the Centaur stage to improve mission flexibility and reliability, and to provide three-burn, synchronous orbit capability. The addition of a sidewall radiation shield significantly - reduces heat transfer to the liquid hydrogen o tank. This radiation shield, in conjunction with a newly developed computer controlled propellant tank venting and pressurization system, permits the use of improved techniques for propellant management during orbital coast. Relatively few changes were required for the propulsion and propellant systems in order to adapt them for the synchronous orbit trajectories. Selective redundancy has been incorporated into several systems to improve reliability by reducing the number of single failure points.

A Proof Flight mission will be flown early in 1.974 to demonstrate Titan/Centaur's operational mission capability. In addition, a series of propellant management experiments will be conducted to verify Centaur's capability to coast for extended duration and to complete three-burn, synchronous orbit missions.

\section{Introduction}

The Centaur D-1T is an improved version of the Centaur upper stage which began operational use with the Atlas booster in 1966. Mission capability of the stage will be significantly increased by integration with the Titan IIIE booster, a new integrated astrionics system, and structural and fluid system modifications. An overall view of the Titan/Centaur launch vehicle is shown in Figure 1.

Development of an improved Centaur began in 1969. This stage was to be adaptable to both Atlas and Titan boosters. It was to have a new integrated astrionics system, modularized software, and modifications to provide three-burn, synchronous orbit mission capability. Added impetus was given to the program late in 1969 when the NASA selected Titan/Centaur as the launch vehicle for the Viking mission. In early 1972 a decision was made to proceed with a program intended to improve Centaur system reliability by eliminating single failure points wherever practical. The outcome of these decisions is the Centaur stage known today as the Centaur D-1T.
The Centaur D-1T, shown in Figure 2, uses liquid hydrogen and liquid oxygen as propellants. These propellants are contained in thin-wall, pressure-stabilized tanks, which are separated by a common insulating bulkhead. An aluminized mylar radiation shield was added to the liquid hydrogen tank sidewall to reduce propellant boiloff and to increase Centaur coast capability to support synchronous orbit missions.

A stub adapter on the forward end of the tank provides support for a payload adapter and for an equipment module. Payloads weighing up to 5,440 kilograms $(12,000$ pounds) can be accommodated with this structure. The new astrionics system is mounted on the equipment module. The heart of the astrionics system is an advanced, high speed, Digital Computer Uni.t (DCU), with extensive input and output capabilities. Many former hardware functions have been integrated into the computer software. This serves to increase reliability by eliminating hardware, and to increase mission flexibility, by reducing the time and effort required for mission peculiar changes.

The propulsion, pneumatic, hydraulic and attitude control systems are all mounted on or near the aft bulkhead. These systems are relatively unchanged from earlier versions of Centaur except for component additions or changes because of the reliability improvement program. Thermal control measures, such as radiation shielding or special coatings, were required for several of these systems to insure satisfactory operation after long space coasts.

The new integrated astrionics system has been successfully flown on two operational Atlas/Centaur missions: the Pioneer II launch to Jupiter in April 1973 and the Intelsat IV communications satellite launch in August 1973. The remainder of the modifications required for the Centaur D-1T will be proven on the Titan/Centaur Proof Flight vehicle, TC-1. This vehicle is being checked out at the Air Force Eastern Test Range preparatory to an early 1974 launch.

The primary mission of $\mathrm{TC}-1$ is to demonstrate Titan/Centaur's capability to support operational missions, such as Viking. In addition, the mission will demonstrate the capability of Centaur to coast for extended durations in a zero-gravity mode, and to support three-burn, synchronous orbit missions. 
The Centaur main propulsion system consists of two Pratt and Whitney Aircraft RL10A-3-3 rocket engines, two propellant boost pumps and associated propellant ducting. This system is shown in Figure 3. The RLIOA-3-3 engine is regeneratively cooled and turbopump fed with an altitude thrust of 66,720 newtons $(15,000$ pounds) and a nominal specific impulse of 444 seconds. The propellants, liquid oxygen and liquid hydrogen, are injected at a nominal oxidizer-to-fuel mixture ratio of $5: 1$. The engines are capable of making multiple starts after Iong coast periods in space.

A boost pump in each propellant tank provides the Net Positive Suction Head (NPSH) required by the main engine turbopunps. The boost pumps are turbine driven centrifugal pumps, and are located in sumps at the end of each tank. Hot gas to power the turbines is obtained by catalytic decomposition of hydrogen peroxide. The operating speed of each pump is controlled by fixed metering orifices to maintain a constant flow of hydrogen peroxide to the catalyst bed.

Propellants are transferred from the boost pumps to the engines by stainless steel propellant ducts. The ducts contain gimbal bellows joints to permit engine gimbaling for thrust vector control. The exterior surface of the ducts is covered with foam insulation to minimize heat transfer while the vehicle is on the ground. Multilayer radiation shielding is added over the foam insulation for long coast duration missions to minimize radiation heat transfer to the ducting.

Duct bleed lines are attached to the ducting near each engine inlet valve to bleed gas from the ducting by recirculation flow back to the propellant tank. This improves propellant duct chilldown and boost pump operation during engine prestart sequences.

The RLI0A-3-3 engine turbopumps must be chilled down prior to engine start. In flight, the main propellants are used for chilldown by permitting them to flow overboard through the pumps. In order to reduce the loss of flight propellants for first Centaur engine start, and to reduce the time required between boost vehicle engine cutoff and Centaur engine first start, the hydrogen turbopumps are prechilled with liquid helium prior to launch.

Inflight chilldown is programed for fixed time periods determined by extensive ground test programs. Thermal analyses were conducted to determine the expected range of temperatures at selected locations on both the main engines and propellant ducting. The engine and ducting were then preconditioned to these temperatures and the proper duration of prechill detemined and verified by test.

The primary change to the propulsion system to provide three-burn capability was the addition of radiation shielding to the propellant ducting. This shielding significantly reduces the quantity of propellant and time required for restart chilldown. For example, the present operational Centaur requires 17 seconds of chilldown after a 30minute coast period. The Centaur D-lT will need only 24 seconds of chilldown after a $5-1 / 4$ hour coast period.

\section{Reaction Control and Hydrogen Peroxide Supply System}

The reaction control and hydrogen peroxide $\left(\mathrm{H}_{2} \mathrm{O}_{2}\right)$ supply system is located on the aft bulkhead as shown in Figure 4. It consists of 12 thrusters, $2 \mathrm{H}_{2} \mathrm{O}$ storage bottles, 7 solenoid valves, a relief valve, and associated tubing to the thrusters and boost pump turbines. To permit better understanding of the system, a schematic is shown in $F$ igure 5 .

The reaction control thrusters produce 26.7 newtons ( 6 pounds) of thrust each, and are grouped in four clusters, one cluster in each vehicle quadrant. Each cluster contains two lateral thrusters. In addition, quadrants 2 and 4 each contain two axial thrusters. The lateral thmusters are used for pitch, yaw and roll control, while the axial thrusters are used for propellant management and retromaneuvers. Vehicle stability is maintained if one engine fails to fire because of the particular engine locations and the attitude control logic software.

Each $\mathrm{H}_{2} \mathrm{O}_{2}$ storage bottle contains a positive expulsion bladder, and has a usable capacity of $108 \mathrm{kilograms}$ (238 pounds). The bottles are pressurized with helium regulated to a pressure of 207 newtons/square centimeter (300 pounds/square inch) from the airborne supply prior to launch. Ground operated, series-redundant valves are used to pressurize and vent the bottles.

The reaction control clusters are interconnected by a manifold line from the supply bottles to each cluster. A closed loop supply line provides a redundant flow path to each cluster such that blockage of the supply line at one point can be tolerated. These supply lines, as well. as the boost pump supply lines, are heated by constant power electrical heaters to maintain proper temperature during flight.

The two flow control valves for the boost pump turbines are connected in parallel such that a failure of one valve to open can be tolerated. A redundant feed path is provided to the hydrogen boost pump to preclude 
the most likely mode of failure, which is freezing of the feed line caused by a cryogenic leak. No redundant feed line to the oxygen boost pump was provided because a significant increase in system complexity would result; instead, this line is protected by special shielding. Finally, a helium purge is used to push the residual $\mathrm{H}_{2} \mathrm{O}_{2}$ from the feed lines after the boost pumps are shut down. This assists in preventing frozen lines during the inactive coast periods. A series-redundant purge valve provides positive shutoff of the purge gas during boost pump operation.

The redundant valves and feed paths were added to the $\mathrm{H}_{2} \mathrm{O}_{2}$ supply and reaction control system to increase system tolerance to the most probable causes of failure, and thus improve the overall reliability of the stage.

\section{Hydraulic System}

Two separate but identical hydraulic systems are used on the Centaur vehicle to gimbal the RLI0 engines for vehicle steering. Each system consists of two servoactuators, one power package, a manifold, and tubing as shown in Figure 6 .

The power package contains a high pressure, main engine driven pump, and a low pressure, electric motor driven pump. The pumps are both constant displacement, vane type pumps. Excess flow from either pump is returned to the reservoir by the appropriate relief valve. Check valves isolate the pumps from each other. One of the improvements in the Centaur D-IT system is the elimination of an accunulator. Analysis and testing showed that the relief valves operate faster than the accumulator, and thus damp out surges. Elimination of the accumulator was a step towards increasing the reliability of the system.

Each of the two servocylinders consist of a servovalve, actuator, and feedback transducer. The actuator is a standard design actuator with thermal insulators to protect the body from the cold RLlo engine. The feedback transducer is a variable reluctance type. The servovalve is a new design to Centaur. It is termed a jet pipe type flow control valve. It replaces a derivative pressure feedback valve. The damping formerly provided by the derivative pressure feedback servovalve is now provided in part by an actuator piston bypass orifice and in part by the vehicle servoamplifier.

One of the major problems with hydraulic systems is susceptibility to contamination. The jet pipe valve reduces concerm in this area because it has significantly larger passages than the derivative pressure feedback valve. For example, a particle 200 microns, (0.008 inches) in diameter will pass through the jet pipe valve, while a particle one/fourth that size will clog the derivative pressure feedback valve. In addition, nozzle blockage of a typical nozzle-flapper type valve always results in a hard-over failure. Nozzle blockage of a jet pipe type valve normally results in a return to null. Depending on when in flight such a failure occurs, the Centaur stage might well survive.

\section{Propellant Tank Venting and Pressurization}

The Centaur liquid hydrogen and liquid oxygen propellants are contained in thin-wall, pressure-stabilized tanks. Pressures in each tank are maintained by propellant boiloff. Vent valves are used to control pressure levels during tanking and flight. All of the vent valves are of the same design, differing only in pressure setting. A solenoid in each valve may be energized to place the valve into a shutoff mode to preclude venting.

The liquid oxygen vent system is mounted on the aft bulkhead and consists of one vent valve, insulated ducting, and a vent disconnect. This system is shown in Figure 7. Venting on the launch pad occurs through the disconnect and a duct which penetrates the interstage adapter. After separation from the Titan booster, venting will occur overboard through the ducting. The ducting is aft canted, and adjustable (prior to launch) such that the thrust from the vented gas is directed through the vehicle center-of-gravity. This orientation minimizes disturbing torques while venting.

The liquid hydrogen vent system is located on the forward bulkhead as shown in Figure 8. It consists of two vent valves, a plenum, ducting, two aft canted vent nozzles, and two inflight vent disconnects. Venting on the launch pad and during ascent prior to Centaur Standard Shroud (CSS) separation occurs through one leg of the vent system and overboard through a shroud-mounted vent fin. After cSS jettison venting occurs through both legs of the system.

This system is symmetrical, which provides equal thrust forces from the two yent nozzles. The nozzles are canted aft $30^{\circ}$, so that a positive forward force is produced on the vehicle. In the event the propellants are not completely settled at the time of venting, or if there is some liquid entrained in the vent gas, the additional thmust will help settle the propellants and reduce any problem.

Two vent valves are used to control hydrogen tank venting. The primary vent valve controls the tank pressure during most of the prelaunch and flight operations. However, a requirement exists during boost flight for a higher tank pressure to react flight loads. The secondary valve is set to operate at a higher pressure level than the primary valve, and serves as a relief or safety valve 
during this period of flight. A solenoid has been added to the secondary vent valve in order to disable the valve during the long zero-gravity coast periods. This permits higher tank pressures to be attained, and reduces the number of tank vent sequences. Except during the boost phase of flight, the vent valves are controlled by a system known as the Computer-Controlled Vent and Pressurization System (CCVAPS). This system will be discussed in detail in the section termed Propellant Management.

The pressurization system provides NPSH for the propellant boost pumps during periods of low gravity operation. This system is shown in Figure 9 and consists of a helium storage sphere (two for TC-1), five solenoid valves (seven for TC-1), check valves, control orifices, tubing, an energy dissipator for the hydrogen tank, and a bubbler for the $\mathrm{LO}_{2}$ tank. See $\mathrm{F}$ igure 5 . The solenoid valves are controlled by the cCVAPS software program.

The solenoid valves are manifolded such as to permit operation which is tolerant of a single valve failure. The manifold configuration consists of a control valve, a primary and a backup $\mathrm{LO}_{2}$ tank pressurization valve, and a primary and backup $\mathrm{LH}_{2}$ tank pressurization valve. For the Proot Flight vehicle, which has four burns, two additional valves, together with larger control orifices, are added for the $\mathrm{LH}_{2}$ tank (primary and backup). These valves and ${ }^{2}$ orifices are required because of the large tank ullage and low helium bottle pressure prior to the last firing. The normal mode of operation is to open the control valve and then the primary $\mathrm{LO}_{2}$ or $\mathrm{LH}_{2}$ valve or both as required. If a valve failure is detected, the control valve is deenergized and the backup valves are used for pressurization.

An energy dissipator is installed on the $\mathrm{LH}_{2}$ tank forward door to reduce the velocity of the helium gas entering the tank. This minimizes disturbance of the surface of the liquid hydrogen, which otherwise would cause some of the hydrogen to mix with the helium gas. This mixing would reduce the gas temperature, and in turn would increase helium requirements.

Helium enters the $\mathrm{LO}_{2}$ tark through a perforated tube called a bubbler located beneath the surface of the liquid oxygen. This new, unique and relatively simple method of pressurization vaporizes oxygen and reduces the helium required for tank pressurization. Bubbler pressurization was determined by a full scale test program to be reliable, controllable and predictable.

\section{Propellant Management}

Coast phase propellant management is required with the centaur vehicle to permit controlled venting of the cryogenic propellant boiloff and to insure proper propellant location and conditioning for engine start.

The current operational Centaur coasts with a continuous low level thrust applied to retain the propellants at the aft end of the tank. The propellants must remain settled because of the need to vent the $\mathrm{LH}_{3}$ tank frequently, starting soon after engine cutoff. Coast time is limited by the propellant boiloff and by the hydrogen peroxide consumption of the settling thrusters. Heat transfer to the liquid hydrogen tank during coast will be reduced from 11,200 watts $(38,200 \mathrm{BTU} /$ hour $)$ to 910 watts $(3,100 \mathrm{BTU} /$ hour $)$ by the addition of the tank sidewall radiation shield and by multilayer forward bulkhead insulation. This reduction in heat transfer means a significant reduction in liquid hydrogen boiloff and in venting requirements of the hydrogen tank. In fact, analysis indicates that only one hydrogen tank vent should be required during the 5-1/4 hour coast to synchronous altitude.

Because of this infrequent need to vent the liquid hydrogen tank, the Centaur D-1T will use a zero-gravity coast mode when coast periods longer than 30 minutes are necessary. In this coast mode, axial thrust will be applied to the vehicle only to settle the propellants prior to engine start and prior to and during propellant tank venting. At all other times the vehicle will be permitted to coast relatively undisturbed, except that vehicle position will be maintained broadside to the sun. Attitude position tolerances will be reasonably large so as to minimize attitude control system propellant usage. Approximately every 30 minutes the vehicle will be rolled 180 degrees to provide some solar heating to all components in order to maintain their temperatures within acceptable limits.

The CCVAPS mentioned earlier controls tank venting and pressurization. A block diagram is shown in Figure 10. Three ullage pressure transducers per tank provide input to the CCVAPS software program. This program makes failure checks upon the transducers and pressurization valves, and will operate satisfactorily if one $\mathrm{LH}_{2}$ and/or one $\mathrm{LO}$ transducer fails, or if one pressurization valve fails.

During a zero-gravity coast mode the cCVAPS continually monitors tank ullage pressure. Upon reaching preselected values, a vent sequence is initiated. First, two of the axial thrusters are fired for a period of time to settle the propellants. Subsequently, the two remaining axial thrusters are fired and the tank vent valves are enabled to vent. After the desired pressures are reached, the vent valves are relocked and the settling thrusters shut off. The vehicle then returns to the zero-gravity coast mode.

The CCVAPS software program also controls tank pressurization. Tank pressurization is 
necessary to provide NPSH for the propellant boost pumps prior to engine start. Tank ullage pressures are determined by the program just prior to start of pressurization. A delta pressure value is added to the measured pressure value to determine the desired final ullage pressure for each tank. The pressurization valves are then opened and closed as necessary to obtain the desired pressure. The system is disabled after engine start because propellant boiloff and the gravity head produced by vehicle acceleration provide sufficient NPSH for the boost pumps. The CCVAPS software program replaces a program where the pressurization valves were opened for predetermined periods of time. Since these time periods had to be determined prior to flight, there were significant variations in ullage pressure rise. In addition, in order to provide for all variables more helium was used than necessary. Since the storage of gaseous helium is very inefficient (the ratio of usable helium weight to storage system weight is 0.10 ), it is very advantageous to minimize the quantity of helium required by controlling the tank pressure levels with a system like the CCVAPS.

\section{Titan/Centaur Proof Flight}

The first flight of the Titan/Centaur vehicle, TC-1, is a Proof Flight designed to demonstrate the capability of the vehicle to support operational missions, such as Viking. In addition, the mission will demonstrate the capability of the centaur stage to coast for extended duration in a zero-gravity mode, and to support three-burn, synchronous orbit missions.

The Proof Flight trajectory is shown in Figure 1.l. The initial phase of flight, through start of second-burn, will simulate the Viking mission trajectory. The second Centaur main engine cutoff (MECO) will occur early in order to maximize the quantity of propellant remaining in the tanks for the subsequent propellant management experiments.

After second MECO, the Centaur vehicle will be programued into a low earth orbit zero-gravity coast of approximately 80 minutes duration. The third Centaur burn will place the vehicle in a transfer orbit to near-synchronous altitude. The vehicle will coast in this transfer orbit for approximately $5-1 / 4$ hours, until an altitude of 34,300 kilometers $(18,500$ nautical miles) is reached. True synchronous orbit altitude will not be attained by design to avoid placing an inactive payload in the active synchronous orbit corridor. A fourth Centaur burn will be made to demonstrate the capability of Centaur to perform an operational three-burn synchronous orbit mission.

At the end of each of the zero-gravity coast periods, two of the axial firing thrusters will be commanded on to settle the propellants at the aft end of the tanks. After sufficient time has elapsed to assure settled propellants, the propellant tanks will be vented to saturate the propellants at the proper pressure level. Next, the tanks will be pressurized with helium to provide boost ! pump NPSH, followed in succession by boost pump start, engine chilldown, and engine start. Tank venting and repressurization are necessary to assure sufficient NPSH for proper boost pump operation.

After fourth MECO, a boost pump experiment will be attempted. The propellants will be settled, the boost pumps turned on, and engine chilldown initiated. The propellant tanks, however, will not be pressurized. The boost pumps are designed to handle mixed phase flow, but by specification require some positive NPSH. Ground tests have verified the capability of the pump to operate satisfactorily with essentially saturated fluid. However, it is difficult to eliminate the gravity head during ground tests. Hence, this experiment will help determine the true NPSH requirements of the boost pumps. The hoped-for result is, of course, a reduction in the quantity of helium required for tank pressurization prior to engine start.

In summary, the development effort of the past several years has resulted in several significant changes to the Centaur stage. These changes have enhanced mission capability of the Centaur, and represent an increase in inherent reliability of the vehicle through reduction of single failure points and by substitution of more reliable components. Further, some of the concepts employed on the Centaur D-1T appear to be applicable to a cryogenic Space Tug. These concepts will be proven during the Titan/Centaur Proof Flight mission in early 1974 . 

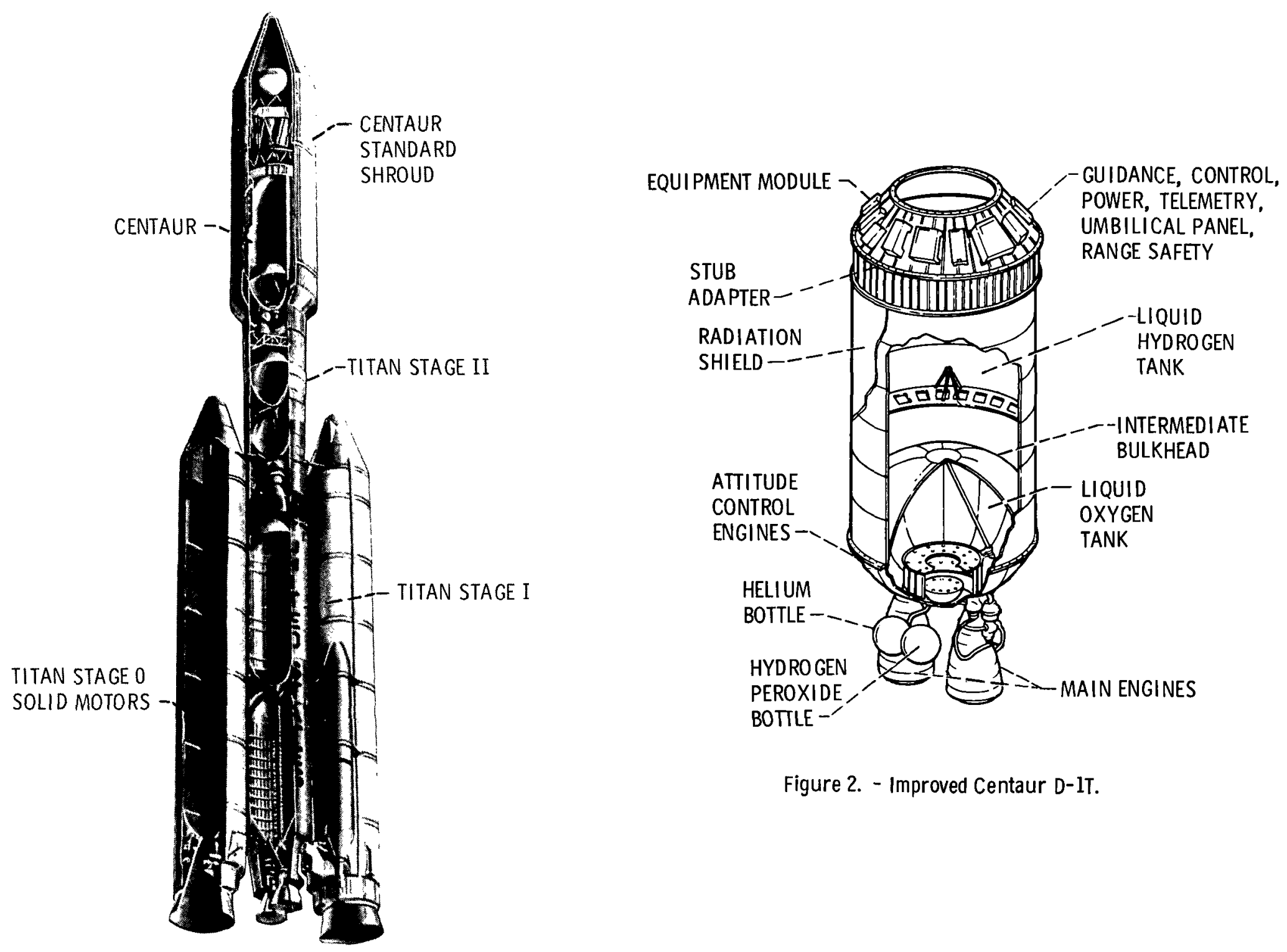

Figure 2. - Improved Centaur D-1T.

Figure 1. - Titan/Centaur launch vehicle. 

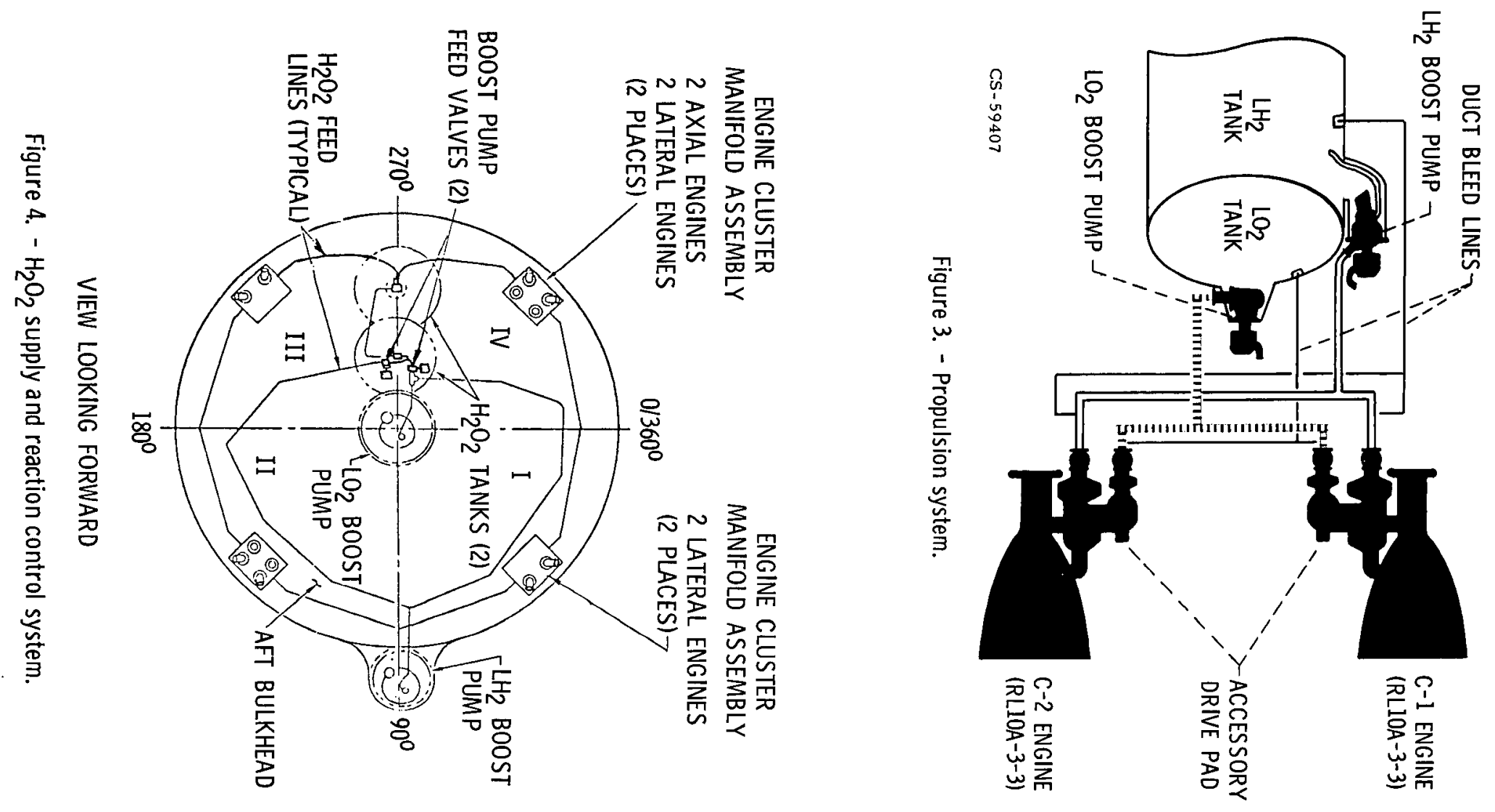


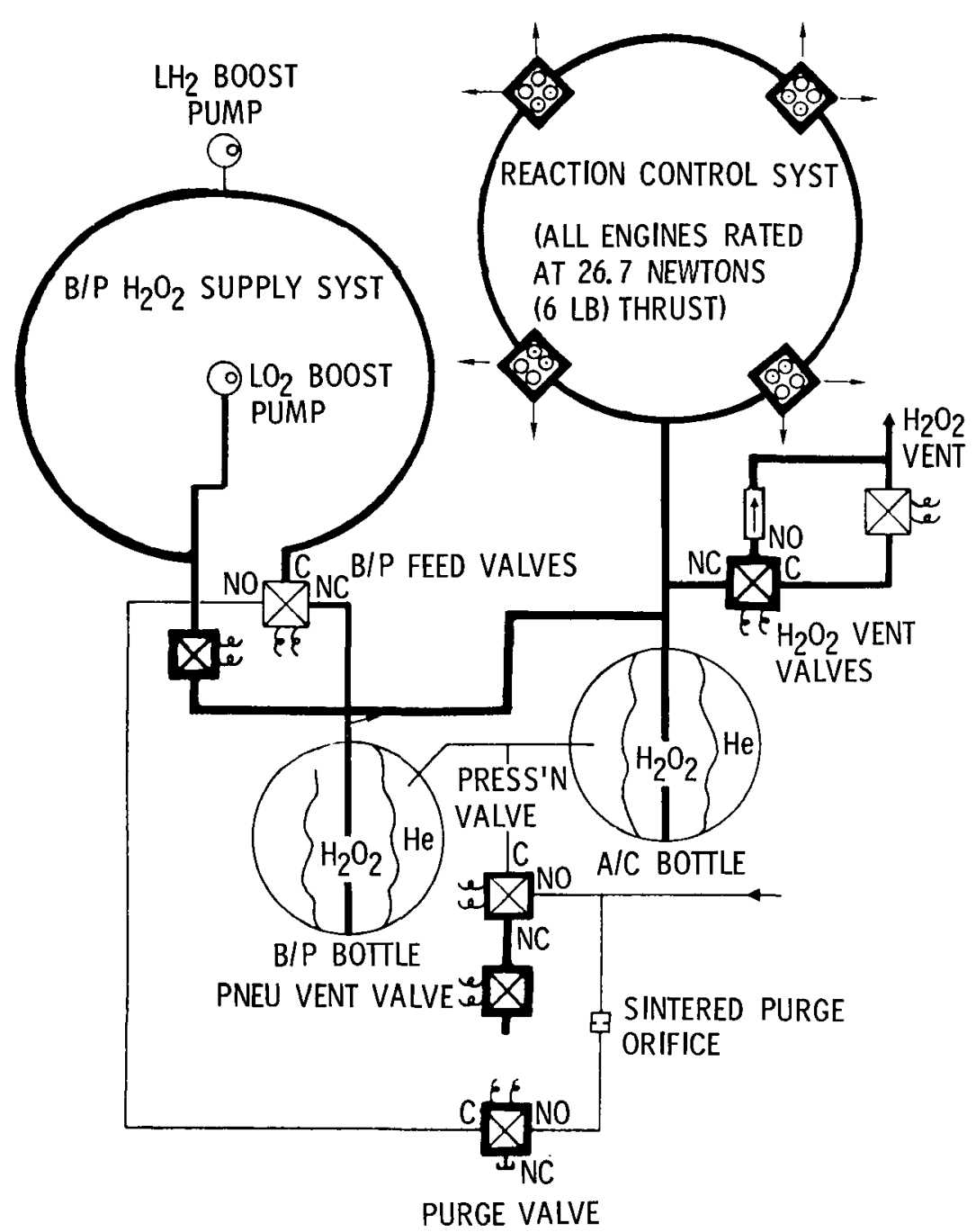

Figure 5. - Reaction control and hydrogen peroxide supply system schematic.

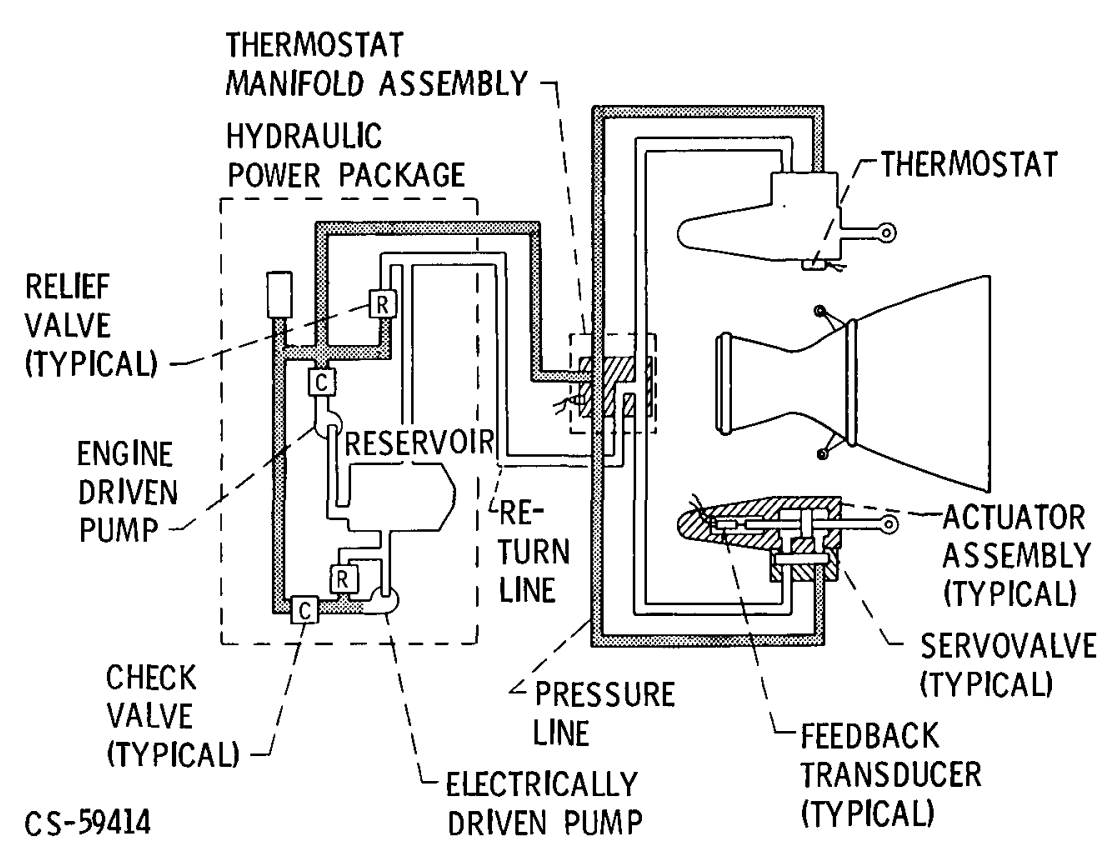

Figure 6. - Hydraulic system. 

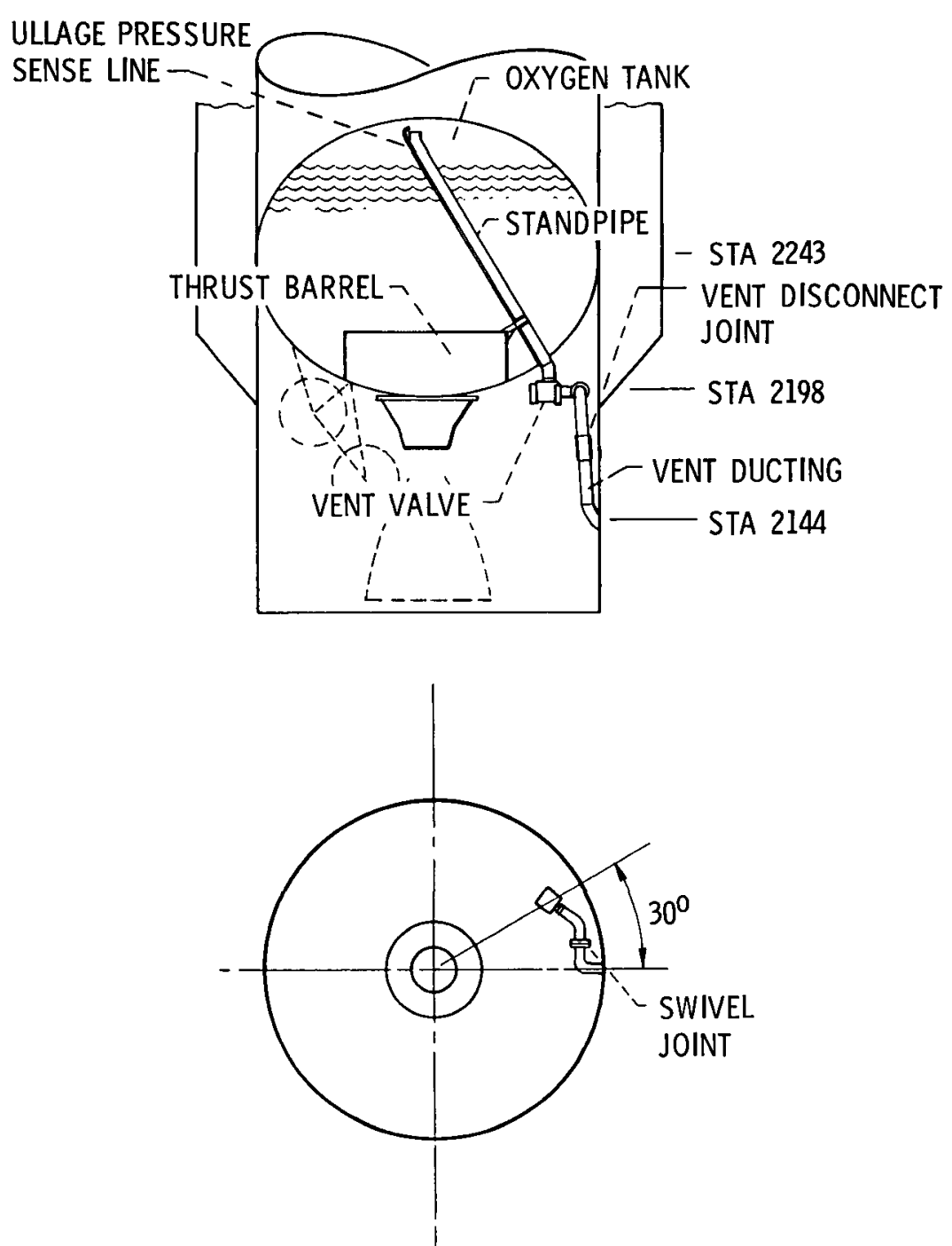

VIEW LOOKING FORWARD

Figure 7. $-\mathrm{LO}_{2}$ vent system.
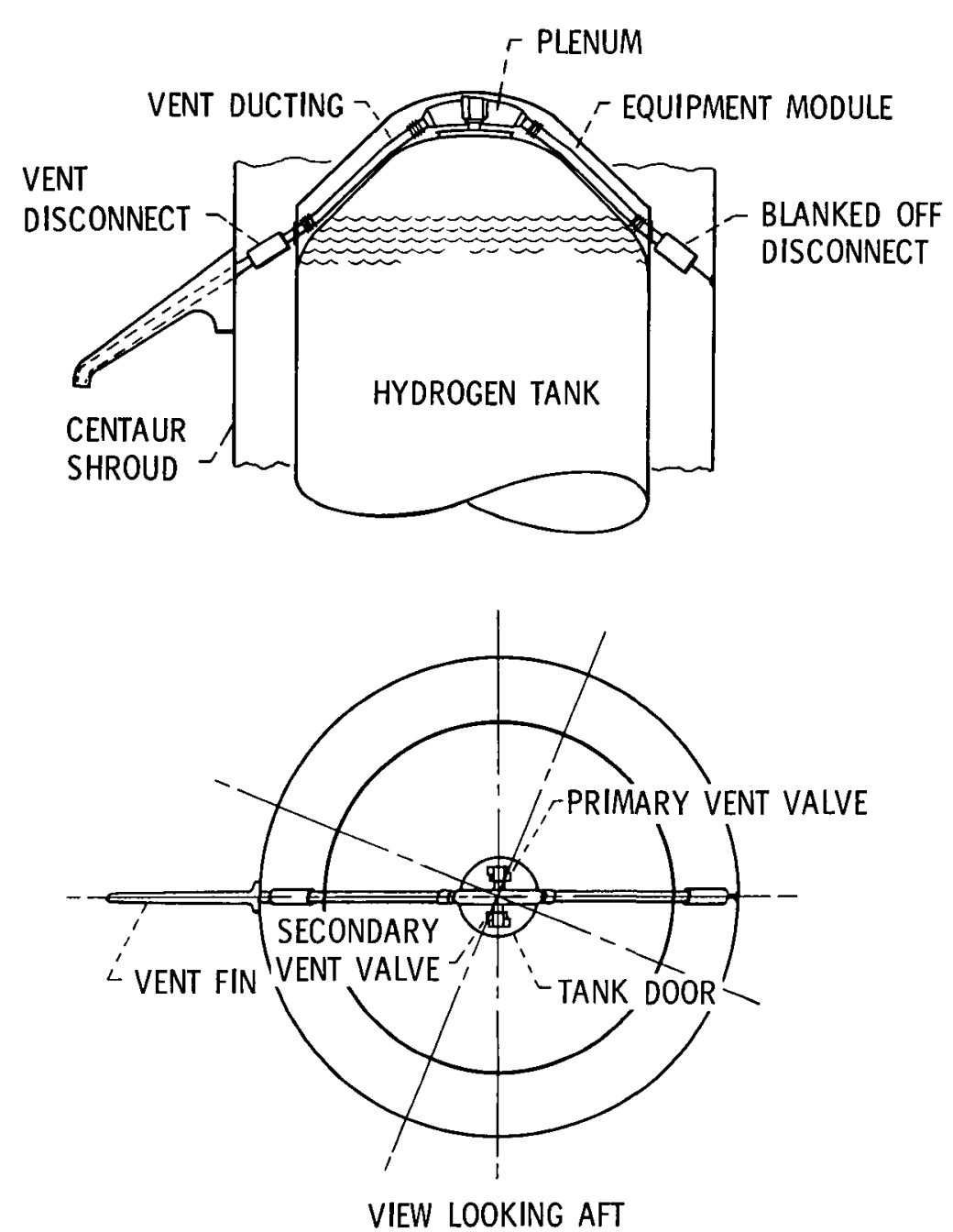

Figure 8. - $\mathrm{LH}_{2}$ vent system. 


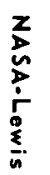

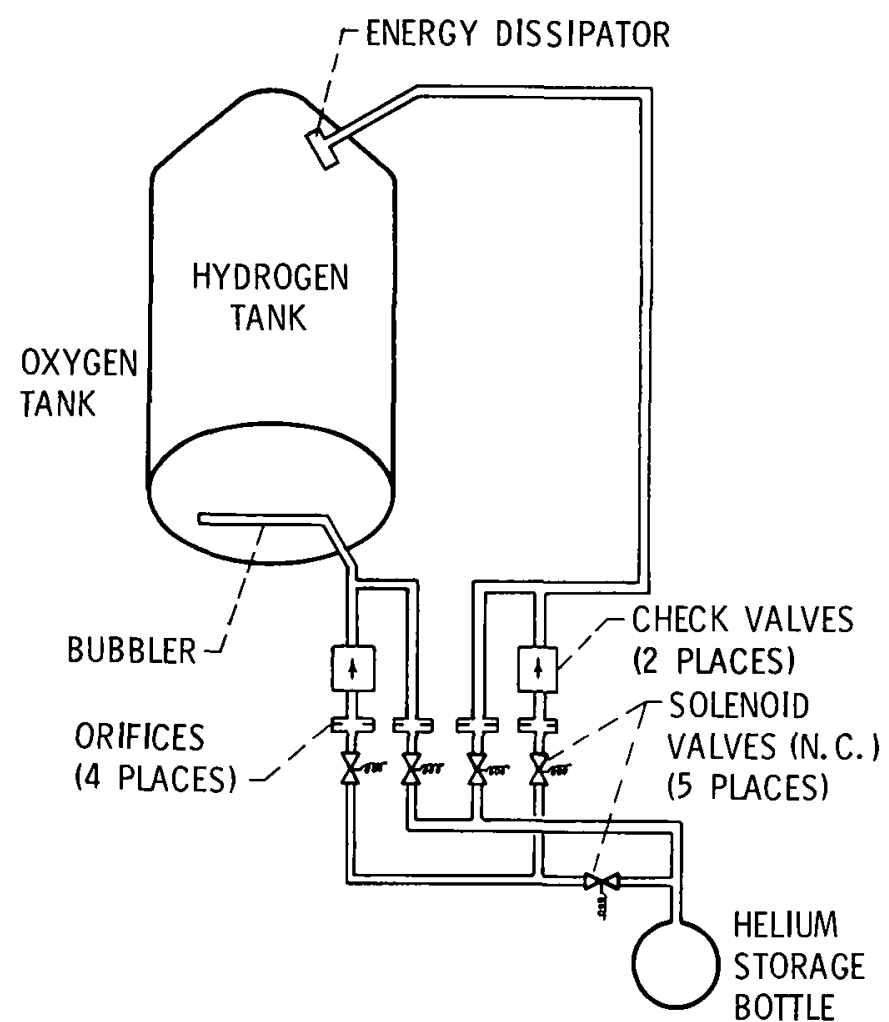

Figure 9. - Pressurization system (standard Centaur D-IT configuration).

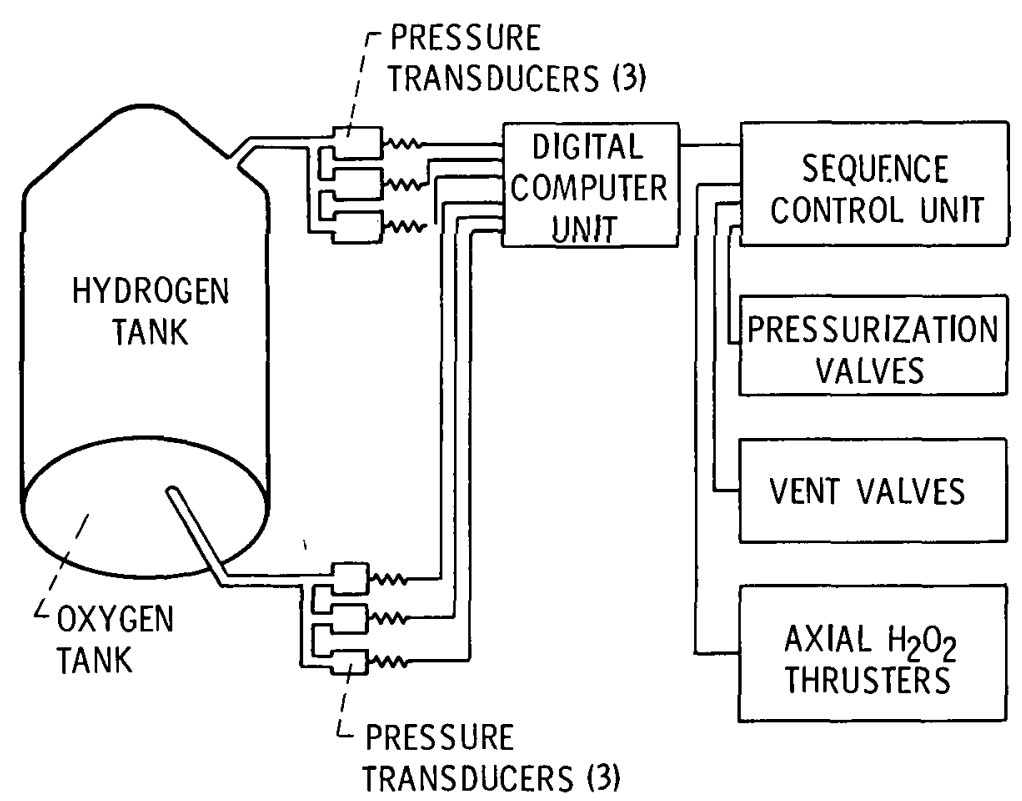

Figure 10. - Computer controlled vent and pressurization system (CCVAPS).

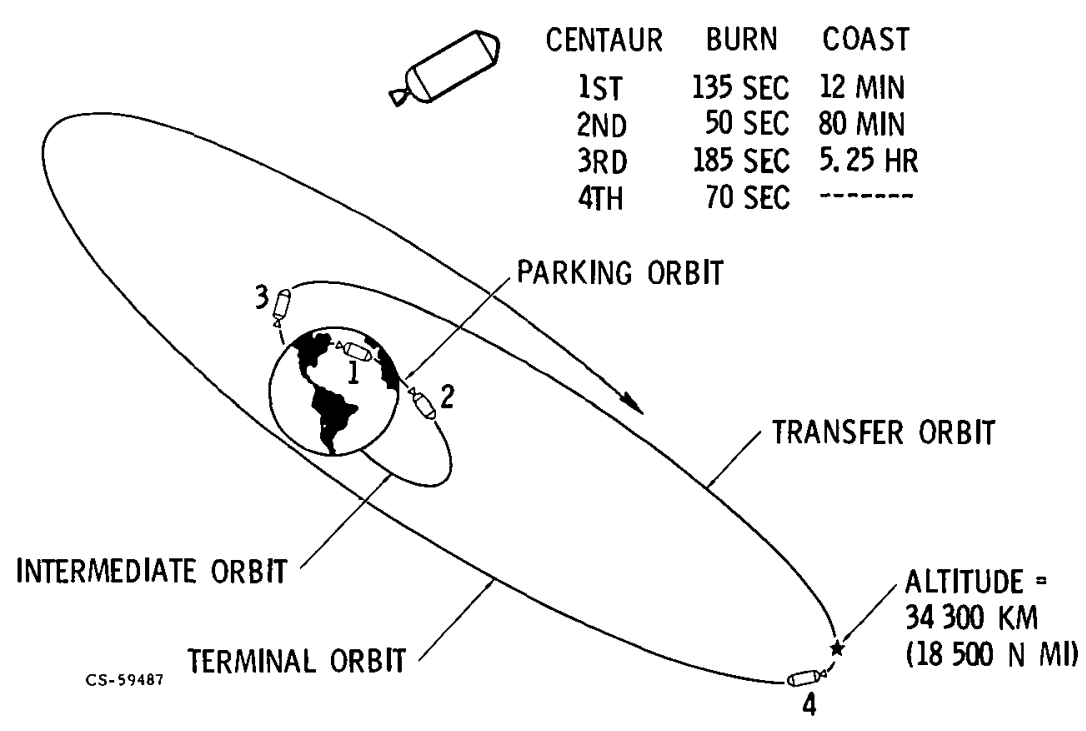

Figure 11. - Titan/Centaur proof flight trajectory. 